\title{
A Preliminary Study on the Introduction of Creative Thinking Training in the Teaching of Design Methodology Shengli Chen ${ }^{1, a^{*}}$ and Jinsong $\mathrm{Yu}^{2, \mathrm{~b}}$
}

\author{
${ }^{1}$ School of Design, Jianghan University, Wuhan, China \\ ${ }^{2}$ School of Art and Design, Wuhan University of Science and Technology, Wuhan, China \\ a*527395960@qq.com, ${ }^{\text {b }}$ yujinsong@wust.edu.cn
}

Keywords: Carrier; Creative thinking; Teaching model

\begin{abstract}
The rapid development of art design education, the training of creative thinking is a lso more and more attention. The teachers in our college try to the curriculum of design meth od as the carrier with professional events, the students' collaborative design; student-centered, $t$ eacher supplemented by open teaching, students, teachers, professional judges third-party evalu ation, to links creative thinking training into teaching, mobilizing students' initiative, developin g students' creative thinking and improving teaching effect.
\end{abstract}

\section{Introduction}

Since the rise of industrial design discipline, design methodology has been one of the indispensable theoretical courses in art design since it is instructive in designers' creative design activities. It is also the key to the discipline construction and development of major art design institutes. At present, most teaching and research personnel in art and design colleges discuss the design methodology from the perspectives of design theory, development trend and function. However, there is not much research on the nature of creative thinking, ie, "how to create". The process of the art design is a process of creative design thinking: the scientific nature of design determines the logical orientation of designing creative thinking, and the artistic nature of design leads to the thinking of design in the form of images. This feature also shows that any single way of thinking can't solve the design problem, which is the focus of design methodologies. Therefore, the significance of choosing design methodology lies in: Firstly, it is necessary to clarify the teaching reform and practice of creative thinking curriculum in art design discipline. Secondly, discuss the teaching methods of creative thinking course in art design discipline. Third, to construct a feasible teaching mode of creative thinking training in this course.

\section{Art Design and Creative Thinking Training}

Art Design Education Model. In recent years, the reform of teaching in the second-batch universities has gradually established the goal of personnel training of applicability, creativity and internationality based on the characteristics of students and the needs of society. In our country's current education system, there are roughly two types of art design education modes: one is a comprehensive university, a professional art college, and a teacher-training college, with an emphasis on art theory and art training; another Is based on a variety of engineering colleges, such as construction, machinery, light industry, textile and other disciplines, pay attention to professional crafts and technology training. This pattern of characteristics can be clearly observed from the differences in the courses they teach. Both of these two modes of education have advantages and disadvantages, which they may learn and complement each other to a certain extent. However, due to the limitations of the current education management system, professional art colleges, comprehensive universities and engineering colleges belong to different administrative departments. This difference directly leads to the difference of students' knowledge structure: the students come from liberal arts college students who lack the professional craft and professional technical training; while the students who come from the science college entrance exam students lack the theory and art of fine arts Basic training. Thus, the students' knowledge system is 
fragmented due to the difference of academic background. In the teaching method, it lacks new ideas because of too much emphasis on the cultivation of students' individual skills, let alone cultivation of students' creative thinking. It is initially understood that at present, except for the Tsinghua University Academy of Fine Arts, there are almost no art education schools in the nation that offer creative thinking training courses. In view of this, the teachers engaged in art design education in colleges and universities should change their concept: from cultivating students 'individual skills to cultivating students' teamwork ability; from loosely changing knowledge structure to strengthening knowledge integration and solving problems in design practice; Emphasize the transformation of students' professional knowledge into interdisciplinary and general education. Therefore, it is especially urgent to open training courses aimed at cultivating students 'creative thinking ability, to explore new teaching methods, to cultivate students' creative abilities and to effectively integrate them into the teaching of different specialized courses.

According to the characteristics of students and the professional characteristics of art design, the second-batch university where the author is located is closely linked to the training objectives of "three-personality" talents. Based on the professional core curriculum "Design Methodology", they have been discussing the teaching methods" How to Cultivate Creativity Thinking ". With the joint efforts from the teachers of the course group, the current teaching mode with thematic training as the core which contained the teachers' teaching, guidance and classroom discussion has been basically established and achieved remarkable teaching results.

Training Objectives and Teaching Methods. The whole course teaching consists of two subject training. Since this course is the first major course in the overall progress of student course study, it is not easy for students to switch from the basic course design thinking to creative thinking at the beginning of the study, The students in grasping and using creative thinking methods to is not ideal; Based on the problems encountered in the training of the previous subject, the instructor will lead the students to analyze and summarize them at the beginning of the next subject training so that they can quickly enter into the new round of subject training with understanding and cognition, Extremely significant. The thinking of the students was obviously broadened, and the design and presentation skills of the subject were also greatly improved. Students also generally agree with the whole course of study in the process of training topics. However, compared with domestic and foreign art schools which are already relatively mature in this field, there are some shortcomings in the teaching of design methodology courses in our college. First of all, we can't keep up with changes in the curriculum aids, such as video materials, references, online information updates are not timely enough. Second, the concern reality of the issue is also inadequate. Third, with the matching teaching effectiveness and quality evaluation system, standards and methods are not perfect enough.

\section{Construction to the Mode of Creative Thinking Teaching}

Creative thinking courses for art students in the design is to tap and cultivate the possibility of individuality and individual potential, to affirm the unique existence of the individual value of students, to ensure that every student with normal intelligence can be maximized. To achieve this goal involves at least three elements including personality, ability and research. Individuality is a prerequisite for innovation, and having a reasonable knowledge structure is also the basis for innovation. In order to effectively solve the relationship among the three, the combination of compulsory and optional courses should be adopted in the curriculum: the basic objective of ensuring compulsory education is to take general education as a compulsory course; elective courses based on professional training are helpful for students to construct Reasonable knowledge system, so that students have a strong adaptability to the new situation. At the same time, through the rational adjustment of teaching content to explore student interest and talent and give full play to their strengths. Second, through the miniaturization of the curriculum to allow students to have more opportunities to choose the relevant subject courses, but also can be entered into the subject design by incorporating some real-life topics closely related to students, not only guide students to 
focus on life in the design, and Learn to find more convincing design basis in real life, and let students understand the practical significance of using design to solve practical social problems. Finally, by developing comprehensive programs, students develop the ability to integrate knowledge and apply knowledge to solve problems.

\section{Exploration of the Teaching Mode of Creative Thinking Training}

Exploration of Teaching Mode. In recent years, our college has focused on the characteristics of students' origins and the characteristics of art design specialty in the second-batch university and closely followed the training goal of "three-personality" talents. In our teaching, we have always discussed the purpose and significance of cultivating creative thinking. , As the core course of this major, Design Methodology is currently used as a carrier to explore creative thinking training teaching mode in our college This course is intended to teach students the theory of design methodology of scientific systems to stimulate students' creative thinking and to apply them to problem-solving exercises to solve problems effectively. It also explores the rules and methods of creative thinking in the process of art design and understanding of creativity in innovation Design of the operating mechanism. In practice, the course of "Design Methodology" teaching is based on the subject training content, classroom teaching and student group discussion. Teachers selectively implanted subject exercises to train Students' thinking and design methods in the teaching process, the theoretical study and design practice into one, and strive to maximize the optimization of teaching effectiveness. Through this course, students will understand and master design methodology, improve their creativity and lay the foundation for further professional study.

The Theory of Design Method and Creative Thinking. The "Design Methodology" course always combines the theory and practice in the teaching idea: the first stage is the systematic study of the design method theory; the second stage is the concrete application of the design thinking and the method. Throughout the process, students apply abstract theoretical knowledge to specific design processes to ask questions, analyze problems and find solutions to problems so that students can understand design theory and methods in depth.

Not only that, the teaching methods of this course are also introduced into the teaching of other specialized courses and have achieved good results. In recent years, the subject of training has won many awards at all levels of design competitions: the training project from product design combined the 2011 "creative Xiaoshan - National Decorative Sanitary Product Design Competition" to gains including Gold Prize, Silver Prize, Creative Prize and Encouragement Prize. Combining with the fifth Hemudu Cup China Small Appliances Innovation Design Contest in 2011, the training achievement has won the Gold Medal and Outstanding Prize again. The above results not only strongly support the operability of the design methodology teaching model, but also show that the subject training can enable students to effectively accept the design theory to enhance the ability to solve design problems.

\section{The Value and Significance of Creative Thinking Training Teaching Mode}

The Practicality of the Training of the Subject. After years of exploration, our college has gradually formed the main task of integrating subject training with events in the teaching of design methodologies, and the characteristic teaching mode has been adopted in the teaching of theory so as to promote the renewal cycle of the subject training contents and ensure that the subject training is more Strong practicality. On the one hand, during the course training, the instructors lead the students to carry out research and information collection, use the theoretical method of creative thinking to conduct a comprehensive analysis of the events and define the design goals; use the creative thinking mechanism to analyze the design environment and achieve Innovative design purposes. On the other hand, the theoretical teaching of design methodology runs through the whole teaching process. The teaching includes the general guiding principles of design methodology, the specific methods and tools involved, and the principles to be followed. In solving the problem of different types of design issues, lecture teachers organize students to brainstorm 
collision sparks. The orderly guidance of design methodology to the whole design process is conducive to the development of creative thinking and creativity, and the continuous accumulation of creativity can generate new ways and means. In this sense, the method of creative thinking is the method of the formation of creative thinking, which is the main, basic and typical form of creative thinking. Different theories of creative thinking have their own systems, but their internal attributes are the same. Their differences lie in different creative thinking methods for different fields. The application of creative thinking in specific cases is essentially the feasibility of verifying the results of creative thinking.

The Implementation of Teaching Mode. The creative thinking training teaching mode based on the "Design Methodology" course in our college is a small-scale trial in the individual student studios. The preliminary results are piloted in the course teaching of art-related design of the whole college. The scope of the response to further promote the teaching of other related courses. The promotion of this teaching mode has brought about a win-win situation for both teachers and students. Among them, students are the largest beneficiary group and teachers. Secondly, the school benefits from living in third place.

\section{The Supportive Environment}

Teachers and faculty members of this course are all full-time teachers in our college, which can fully guarantee the commencement of related preliminary research and the holding of small seminars and other activities. The instructors are graduating students from different art design institutes with reasonable knowledge structure and certain Teaching experience; active thinking in teaching, easy to accept new ideas. All this is for our college creative thinking training teaching mode provides a powerful guarantee. The course design teaching closely linked to the community and business, relying on international and domestic influential design competition, this combination of theory and design practice model allows students to deeply understand the design methodology and can effectively guide the design practice. In addition, our college can also provide practical sites and equipment for the majority of students, is conducive to the development of academic exchanges at home and abroad.

\section{Conclusion}

The teaching mode of creative thinking training experience to easily make the implementation of the fun of learning, and fully mobilize the enthusiasm of learning, stimulate the creativity of students; teachers use the design methodology and concept to guide and inspire students, in-depth communication and produce harmonious learning atmosphere between teachers and students. Based on this classroom environment, we further promote the thinking collision, creative communication between students, teachers, enhance the enthusiasm of students' creative thinking.

\section{Acknowledgements}

This work is supported by the "University Teaching and Research Projects NO: 2013085" which is granted by Wuhan Education Bureau, Wuhan, China, in 2013.

\section{References}

[1] Zheng Jianqi, Design Methodology, Tsinghua University Press, 2009-06-01.

[2] Lu Bainian, Creative Design Thinking, Tsinghua University Press, 2015-10-01

[3] Hu Feixue, Creative Thinking Training and Methods, Mechanical Industry Press, 2009-09-01

[4] [British] Brown; Hou TingTranslates, IDEO, Design Changes Everything: Design Thinking How to Change Organization and Stimulate Innovation, Volumes Publishing Company, 2011-05-01 
[5] Design Methodology, Retrieved June 2017, from https://baike.baidu.com/item/Design Methodology/4902716?fr=aladdin

[6] 5 steps, Simply Put My Product Design Methodology , Retrieved July 2017, from http://www.woshipm.com/pd/407856.html

[7] Zeng, Y. \& Cheng, G. (1991). On the Logic of Design. Design Studies, 12(3), 137-141.

[8] YU, J. S. \& Chen, S. L. (2017). Validation of Recursive Logic in Graphic Design. Journal of Integrated Design and Process Science, v20, n3, p71-85. 